\title{
Efficacy and Safety of Combine Alfuzosin and Finasteride in the Treatment of Symptomatic Benign Prostatic Hyperplasia: A Quasi-Experimental Study
}

\author{
Md. Saifuddin Ahmed Siddique ${ }^{\text {* }^{*}}$ \\ Sharmin Nahar Bashar ${ }^{2}$ \\ Farid Uddin Ahmed $^{3}$
}

'Department of Urology

Chattagram Maa-O-Shishu Hospital Medical College Chittagong, Bangladesh.

${ }^{2}$ Department of Gynae \& Obstetrics Bandarban Sadar Hospital Bandarban, Bangladesh.

${ }^{3}$ Emergency Medical Officer Chittagong Medical College and Hospital Chittagong, Bangladesh.
${ }^{*}$ Correspondence to:

Dr. Md. Saifuddin Ahmed Siddique

Associate Professor

Department of Urology

Chattagram Maa-O-Shishu Hospital Medical College Chittagong, Bangladesh.

Mobile : +88 01819-381326

Email: saifuddinsuza@yahoo.com

www.banglajol.info/index.php/CMOSHMCJ

\begin{abstract}
Background: Lower Urinary Tract Symptoms (LUTS) due to Benign Prostatic Hyperplasia (BPH) are common in elder men and a number of drugs alone or in combination are clinically used for this disorder. To assess the efficacy and safety of combined Alfuzosin plus Finasteride, in patients with LUTS due to BHP. Methods: In this hospital-based, Quasi-experimental study (One-Group Pre test-Post test Design) without Control Groups, 30 consecutive patients were selected as per set criteria for medical management of $\mathrm{BPH}$ with combination of $10 \mathrm{mg}$ Alfuzosin and $5 \mathrm{mg}$ Finasteride, for 12-months, in the outpatient Department of Urology, in Chittagong Medical College Hospital. The primary efficacy criteria were improvement in symptoms (International Prostate Symptom Score (IPSS) peak urinary flow rate and reduction of prostate volume from baseline. Results: Combination therapy with Alfuzosin plus Finasteride was effective in improving the symptoms and peak urinary flow rate from the first follow-up visit (Day 90) in comparison to baseline score. The mean change in the IPSS from baseline at endpoint was $10 \pm 1.87(\mathrm{p}=0.001)$. The percentage increase in the peak urinary flow rate was $4.8 \mathrm{~mL} / \mathrm{s}$, compared with $11.0 \pm 1.82 \mathrm{~mL} / \mathrm{s}$ at baseline $(\mathrm{p}=0.001)$. The patients' quality of life also significantly improved. The percentage decrease in prostate volume at end point was $15.13 \pm 11.3 \mathrm{cc}(\mathrm{p}=0.001)$. Overall, this combination therapy was well tolerated. The incidence of orthostatic hypotension as determined by systematic blood pressure measurements was only 3(10\%). No clinically relevant ejaculation disorders were observed. Conclusion: Alfuzosin plus Finasteride provides effective relief from the symptoms of benign prostatic hyperplasia by reducing the size of the prostate. It is well tolerated from a cardiovascular viewpoint and is not associated with abnormal ejaculation.
\end{abstract}

Key words: BPH; Alfuzosin; Finasteride; IPSS; Qmax; PVR.

\section{INTRODUCTION}

Benign Prostatic Hyperplasia (BPH) is characterized by Lower Urinary Tract Symptoms (LUTS) urinary frequency, urgency, a weak and intermittent stream needing to strain, a sense of incomplete emptying, and nocturia), and can lead to complications, including acute urinary retention ${ }^{1,2}$. BPH is common among older men, with approximately $25 \%$ of men over $40^{3}$. The treatment of symptomatic BPH focuses on relieving the bothersome and irritative symptoms that negatively affect patients' quality of life and inhibiting the clinical progression of the disease.

The treatment approach for BPH has changed since the recent introduction of medical therapies with evidence-based efficacy. The preferred medical treatment for symptomatic BPH is either with a $\alpha$-Blocker (AB) which reduces smooth muscletone in the prostate or bladder neck or a $5 \alpha$ Reductase Inhibitor (5ARI) that reduces prostate volume by inducing epithelial atrophy and apoptosis ${ }^{4}$. Treatment with an $\mathrm{AB}$ or a $5 \mathrm{ARI}$ can ameliorate symptoms and improve urinary flow rate ${ }^{5}$. Finasteride, 
a 5 ARI is more effective on large prostate $(>40 \mathrm{cc})$ than small prostate $(<40 \mathrm{cc})^{6}$. Finasteride also substantially reduces the risk of acute urinary retention and the need for surgery ${ }^{7}$.

The rationale behind combined use of $\mathrm{AB}$ and a 5ARI to control BPH-related LUTS relies on the potential synergistic effect of these two pharmaceuticals agents due to their different modes of action. The theoretical synergy in efficacy and the impact on treatment-related adverse events needed to be clarified by trial results.

However there is scarcity of study in this field in Bangladesh. We therefore, carried out this study to determine the extent that combined Alfuzosin and Finasteride improved urinary symptoms and urinary flow and prevented the progression of $\mathrm{BPH}$ in addition to its relative effectiveness and safety compared with baseline findings.

\section{MATERIAL AND METHODS}

This was a hospital-based, Quasi-experimental study (OneGroup Pretest-Posttest Design) without Control Groups, performed in 30 patients underwent medical management of BPH in the outpatient Department of Urology, in Chittagong Medical College Hospital, Bangladesh. After obtaining approval from the Institute Research Council and Ethics Committee, the study was conducted from May 2007 to October 2008.

\section{Study population}

All consecutive consenting male patients with BPH aged between 50 to 85 years, LUTS with moderate, 8 to 19 International Prostate Symptom Score (IPSS) Maximum flow rate $(\mathrm{Qmax})>10 \mathrm{ml}$ to $<15 \mathrm{ml} / \mathrm{sec}$ on Uroflowmetry (UFR) prostate volume measuring $>40 \mathrm{cc}$ on Transabdominal Ultrasound (US) and Post Void Residue (PVR) $<100 \mathrm{ml}$ on US were eligible for the study after obtaining a written informed consent. The exclusion criteria were the following: use of $\mathrm{AB}$ within 2 weeks/ 5ARI within 6 months or phytotherapy, active Urinary Tract Infection (UTI) bladder outlet obstruction due to any other cause like urethral stricture, bladder neck stenosis or diagnosed to have vesical calculus, urethral or bladder diverticulum, neurogenic bladder, prostatic or bladder cancer, significant Orthostatic Hypotension $(\mathrm{OH})$ post-prostatectomy and renal impairment (Serum creatinine $>2 \mathrm{mg} / \mathrm{dl}$ ).

\section{Intervention}

A standard protocol was used for all our patients. Patients were evaluated with detailed history regarding LUTS. Clinical and digital rectal examination was done. LUTS was assessed using the IPSS questionnaire (English and native language Bangale). Uroflowmetry (UFR) ultrasound of the Kidney, Ureters, Bladder (KUB) and Prostate, with PVR, Serum Prostate Specific Antigen (PSA) Blood Urea, Serum Creatinine, Blood Pressure (BP) in supine and standing position and electrocardiogram were done in all patients at the beginning of the study. Patients were advised to take Alfuzosin 10mg and Finasteride 5mg daily for 12 months. Follow-up was done at 3,
6, 9 and 12 months with LUTS assessment using IPSS, Qmax using UFR and US for PVR and prostate size, side effects of drug and BP in supine and standing positions.

\section{Study endpoints}

The primary endpoints were improvement in IPSS LUTS scores, Qmax and PVR from baseline at 3, 6, 9 and 12 months. The secondary endpoints were ADE to the drugs.

\section{Statistical analysis}

Statistical analysis was performed using SPSS version 12 for Windows. The variables were summarized using mean, standard error, median, and percentages based on the characteristics of the variable. Paired sample $t$ test was used for the analysis of continuous variables. Chi-Square test was used for categorical variables. The $p$ value of $<0.05$ was considered statistically significant.

\section{RESULTS}

The mean age of the 30 patients included in this study was $65.0 \pm 10.02$ years. Other baseline parameters are described in Table 1.

Table 1 : Baseline characteristics.

$\begin{array}{lr}\text { Parameters } & \text { Mean } \pm \text { SD } \\ \text { Age, years } & 65.0 \pm 10.02 \\ \text { IPSS } & 16.5 \pm 2.39 \\ \text { QoL } & 2.40 \pm 0.86 \\ \text { Qmax, ml/sec } & 11.0 \pm 1.82 \\ \text { PVR, cc } & 73.3 \pm 21.62 \\ \text { Prostate weight, cc } & 66.2 \pm 9.47 \\ \text { Serum creatinine, } \mathrm{mg} / \mathrm{dl} & 1.01 \pm 0.89\end{array}$

\section{IPSS}

The mean IPPS (Points) significantly differed $(\mathrm{p}<0.05)$ between baseline and each follow-up, which indicates that after receiving Alfuzosin $10 \mathrm{mg}$ plus finesteride $5 \mathrm{mg}$, IPPS significantly decline in 3 months and it was stable for rest of the study period. The mean IPSS decline varied from 8.9-10.0 points and mean percentage of improvement was varied from $53-60 \%$ points (Table 2 ).

Table 2 : Effect of Alfuzosin with Finesteride on IPSS in different follow-up.

\begin{tabular}{lccccc} 
IPSS (Points) & $\begin{array}{c}\text { Baseline } \\
(\mathrm{n}=30) \\
\text { Mean } \pm \text { SD }\end{array}$ & $\begin{array}{c}\text { Follow-up } \\
(\mathrm{n}=30) \\
\text { Mean } \pm \text { SD }\end{array}$ & $\begin{array}{c}\text { IPSS change } \\
\text { Mean } \pm \text { SD }\end{array}$ & $\begin{array}{c}\text { IPSS change } \\
\text { in \% }\end{array}$ & Mean \pm SD \\
3 Months & $16.5 \pm 2.39$ & $7.6 \pm 1.38$ & $8.9 \pm 2.37$ & $53.9 \pm 5.47$ & $0.001 \mathrm{~S}$ \\
6 Months & $16.5 \pm 2.39$ & $7.0 \pm 1.20$ & $9.5 \pm 2.85$ & $57.6 \pm 6.41$ & $0.001 \mathrm{~S}$ \\
9 Months & $16.5 \pm 2.39$ & $7.1 \pm 0.96$ & $9.4 \pm 2.57$ & $57.0 \pm 4.76$ & $0.001 \mathrm{~S}$ \\
12 Months & $16.5 \pm 2.39$ & $6.5 \pm 0.82$ & $10.0 \pm 1.87$ & $60.6 \pm 5.53$ & $0.001 \mathrm{~S}$ \\
\hline
\end{tabular}

$\mathrm{S}$ : Significant in paired sample t test. 


\section{Qmax}

The mean Qmax $(\mathrm{ml} / \mathrm{s})$ significantly differed $(\mathrm{p}<0.05)$ between baseline and each follow-up, which indicates that after receiving Alfuzosin 10mg plus finesteride 5mg, Qmax significantly increased in 3 months and it was stable for rest of the study period. The mean Qmax increased varied from $2.9-4.8 \mathrm{ml} / \mathrm{s}$ points and mean percentage of improvement was varied from $26-43 \%$ (Table 3 ).

Table 3: Effect of Alfuzosin with Finesteride on Qmax in different follow-up.

\begin{tabular}{|c|c|c|c|c|c|}
\hline$Q \max (\mathrm{ml} / \mathrm{s})$ & $\begin{array}{l}\text { Baseline } \\
(\mathrm{n}=30) \\
\text { Mean } \pm \text { SD }\end{array}$ & $\begin{array}{l}\text { Follow-up } \\
(\mathrm{n}=30) \\
\text { Mean } \pm \text { SD }\end{array}$ & $\begin{array}{c}\text { Qmax change } \\
\text { in } \% \\
\text { Mean } \pm \text { SD }\end{array}$ & Qmax change & $\mathrm{p}$ value \\
\hline 3 Months & $11.0 \pm 1.82$ & $13.9 \pm 0.84$ & $2.9 \pm 1.23$ & $26.4 \pm 3.65$ & $0.001^{\mathrm{S}}$ \\
\hline 6 Months & $11.0 \pm 1.82$ & $15.1 \pm 0.96$ & $4.1 \pm 1.37$ & $37.3 \pm 4.72$ & $0.001^{\mathrm{S}}$ \\
\hline 9 Months & $11.0 \pm 1.82$ & $16.1 \pm 1.06$ & $5.1 \pm 1.12$ & $46.4 \pm 5.51$ & $0.001^{S}$ \\
\hline 12 Months & $11.0 \pm 1.82$ & $15.8 \pm 1.42$ & $4.8 \pm 1.05$ & $43.6 \pm 6.17$ & $0.001^{S}$ \\
\hline
\end{tabular}

S: Significant in paired sample t test.

\section{PVR}

The mean PVR $(\mathrm{ml})$ significantly differed $(\mathrm{p}<0.05)$ between baseline and each follow-up which indicates that after receiving Alfuzosin $10 \mathrm{mg}$ with Finasteride 5mg, PVR significantly decline in 3 months but after that the PVR remain stable. The mean PVR decline varied from $22-23.6 \mathrm{ml}$ points and mean percentage of improvement was varied from 30.0 $32.2 \%$ (Figure 1).

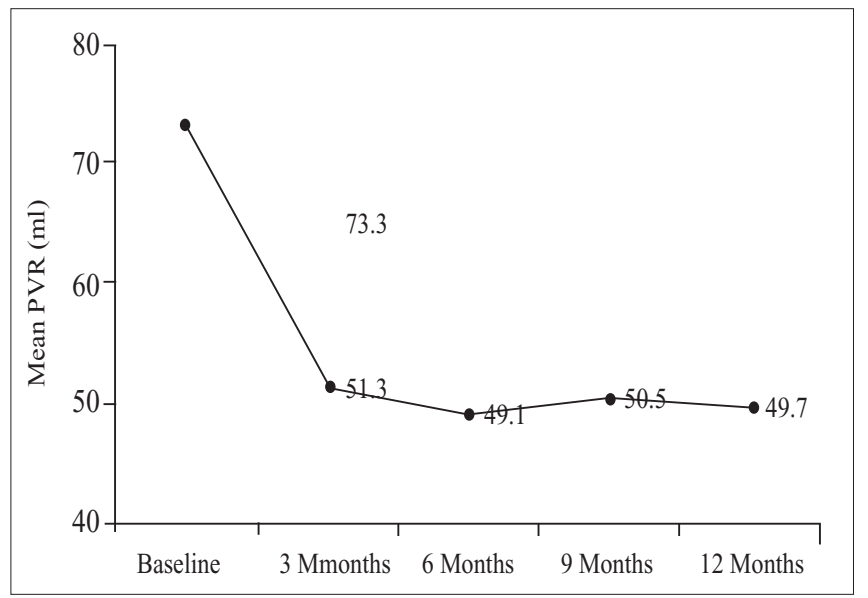

Figure 1: Line diagram showing mean distribution of PVR during baseline and different follow-up of the study patients.

\section{Prostate volume}

The mean prostate volume ( $\mathrm{cc}$ ) significantly reduced $(\mathrm{p}>0.05)$ from baseline to each follow-up, which indicates that Alfuzosin $10 \mathrm{mg}$ with Finasteride 5mg had significant effect in reduction of prostate size. The mean reduction of prostate volume varied from 13.30-15.13 cc points and mean percentage of improvement was varied from $20.1-22.9 \%$ (Table 4 ).
Table 4 : Effect of Alfuzosin with Finesteride on prostate volume in different follow-up $(\mathrm{n}=30)$.

\begin{tabular}{|c|c|c|c|c|c|}
\hline $\begin{array}{l}\text { Prostate } \\
\text { volume (cc) }\end{array}$ & $\begin{array}{c}\text { Baseline } \\
(\mathrm{n}=30) \\
\text { Mean } \pm \mathrm{SD}\end{array}$ & $\begin{array}{c}\begin{array}{c}\text { Follow-up } \\
(\mathrm{n}=30) \\
\text { Mean } \pm \text { SD }\end{array} \\
\end{array}$ & $\begin{array}{l}\text { Prostate volume } \\
\text { change (cc) } \\
\text { Mean } \pm \text { SD }\end{array}$ & $\begin{array}{l}\text { Prostate volume } \\
\text { change in } \% \\
\text { Mean } \pm \text { SD }\end{array}$ & $\mathrm{p}$ value \\
\hline 3 Months & $66.2 \pm 9.47$ & $52.90 \pm 9.01$ & $13.30 \pm 11.2$ & $20.1 \pm 13.50$ & $0.001^{\mathrm{S}}$ \\
\hline 6 Months & $66.2 \pm 9.47$ & $51.81 \pm 8.93$ & $14.39 \pm 10.3$ & $21.7 \pm 14.45$ & $0.001^{\mathrm{S}}$ \\
\hline 9 Months & $66.2 \pm 9.47$ & $51.78 \pm 8.89$ & $14.42 \pm 9.5$ & $21.8 \pm 16.59$ & $0.001^{\mathrm{S}}$ \\
\hline 12 Months & $66.2 \pm 9.47$ & $51.07 \pm 8.94$ & $15.13 \pm 11.3$ & $22.9 \pm 18.39$ & $0.001^{\mathrm{S}}$ \\
\hline
\end{tabular}

NS: Not Significant in paired sample t test.

\section{Adverse Drug Events (ADE)}

ADE was observed in 18 out of 30 patients (60.4\%). Dizziness was the most common side effects. Other common ADEs were headache, hypotension and abnormal ejaculation. The three patients who had complain ejaculatory dysfunction they had the symptom before enrollment. The incidence of ADE reduced with progression of time (Table 5).

Table 5: Adverse effects to Alfuzosin plus Finasteride at 3, 6, 9 and 12 months.

\begin{tabular}{lrr} 
Adverse effect & Follow up Time & n (\%) \\
Hypotension & 3 Months & $3(10 \%)$ \\
& 6 Months & $2(6.7 \%)$ \\
9 Months & $1(3.3 \%)$ \\
12 Months & $2(6.7 \%)$ \\
& & \\
Dizziness & 3 Months & $14(46.7 \%)$ \\
& 6 Months & $15(50 \%)$ \\
9 Months & $16(53.3 \%)$ \\
12 Months & $14(46.7 \%)$ \\
& \\
Headache & 3 Months & $5(16.7 \%)$ \\
6 Months & $3(10 \%)$ \\
9 Months & $4(13.3 \%)$ \\
12 Months & $5(16.7 \%)$ \\
& & \\
Abnormal ejaculation & 3 Months & $3(10 \%)$ \\
& 6 Months & $3(10 \%)$ \\
9 Months & $3(10 \%)$ \\
12 Months & $3(10 \%)$ \\
\hline & &
\end{tabular}

\section{DISCUSSION}

The study confirmed that combined Alfuzosin and Finasteride is effective and safe. Significant improvements in symptoms, and Qmax and decrease in PVR and prostate volume were observed with this regimen from baseline and significant portion of these improvements were observed at the first planned assessment (3 Months). 
The mean baseline IPPS (Points) was found 16.5 \pm 2.39 (Points) in this study and after receiving Alfuzosin with Finasteride, IPPS significantly decline in 3 months follow-up which was $7.6 \pm 1.38$ points, in 6 months follow-up IPPS (Points) was $7.0 \pm 1.20$, in 9 months follow-up IPPS (Points) was 7.1 \pm 0.96 and in 12 months follow-up IPPS (Points) was $6.5 \pm 0.82$. It was also observed that the mean IPSS decline varied from 8.6-10.0 points and mean percentage of improvement was varied from $51-60 \%$ points. In a study to assess the additive benefit of combining an $\alpha 1$-blocker and a $5 \alpha$-reductase inhibitor an European, randomized, double-blind, multicenter trial involved 1.051 patients with lower urinary tract symptoms related to benign prostatic hyperplasia, patients received Sustained Release (SR) Alfuzosin given at a dose of $5 \mathrm{mg}$ twice daily without dose titration, Finasteride, or both drugs, for 6 months ${ }^{8}$. Symptomatic improvement was significantly higher from the 1 st month of treatment with combination, mean changes in IPSS versus baseline at end-point were 6.1. The percentages of patients with a decrease in IPSS of at least $50 \%$ for the combination were 34. In the overall population, increases in Qmax were greater with the combination, compared with Finasteride alone after 1 month of therapy, but changes at endpoint were similar in the three treatment groups.

The mean Qmax $(\mathrm{ml} / \mathrm{s})$ was $11.0 \pm 1.82 \mathrm{ml} / \mathrm{s}$ and after receiving Alfuzosin with Finasteride Qmax significantly increased in 3 months follow-up which was $13.9 \pm 0.84 \mathrm{ml} / \mathrm{s}$, in 6 months follow-up Qmax was $15.1 \pm 0.96 \mathrm{ml} / \mathrm{s}$, in 9 months follow-up Qmax was $16.1 \pm 1.06 \mathrm{ml} / \mathrm{s}$ and in 12 months follow-up Qmax was $15.8 \pm 1.42 \mathrm{ml} / \mathrm{s}$. It was also observed that the Qmax increased was varied from 2.5 to $3.7 \mathrm{ml} / \mathrm{s}$ from baseline to all follow-up and mean percentage of improvement was varied from $22-32 \%$. Van (2000) found in his study that Qmax increased $2.3 \mathrm{ml} / \mathrm{s}$ from baseline in this group. Kirby et al (2003) showed in their study that combined therapy produce statistically significant $(\mathrm{p}<0.05)$ improvements in total Qmax ${ }^{9}$. Hofner (1999) reported in their patients likely to be obstructed, increases in Qmax were significantly higher in both groups (2.9 $\mathrm{ml} / \mathrm{s}$ ), which is closely resemble with the present study ${ }^{10}$.

The present study found that the mean baseline PVR was $73.3 \pm 21.62 \mathrm{ml}$, however after receiving Alfuzosin 10mg with Finasteride 5mg PVR significantly decline in 3 months followup which was $51.3 \pm 11.87 \mathrm{ml}$, in 6 months follow-up PVR was $49.1 \pm 8.90 \mathrm{ml}$, in 9 months follow-up PVR was $50.5 \pm 7.33 \mathrm{ml}$ and in 12 months follow-up PVR was $49.7 \pm 7.05 \mathrm{ml}$. It was also observed that the PVR decline was varied from 72 to $74.4 \mathrm{ml}$ from baseline to all follow-up. The mean PVR decline was higher in 3 months follow-up but the remaining follow-up PVR decline a little. The mean PVR ( $\mathrm{ml})$ was statistically significant $(p<0.05)$ between baseline and each follow-up in these patients, which indicates that after receiving Alfuzosin $10 \mathrm{mg}$ with Finasteride 5mg PVR significantly decline in 3 months followup and the remaining follow-up PVR was almost stable. The mean PVR decline varied from 22.0-24.2 ml points and mean percentage of improvement was varied from 30-33\%. Similar finding was observed by Djavan et al $(1999)^{11}$. The results obtained in this study are comparable with the above author findings.
The baseline prostate volume was observed in this study and found that the mean baseline prostate volume was 66.2 \pm 9.47 cc, however after receiving Alfuzosin 10mg with Finasteride $5 \mathrm{mg}$ prostate volume significantly decline a little in 3 months follow-up which was $52.90 \pm 9.01 \mathrm{cc}$, in 6 months follow-up PVR was $51.81 \pm 8.93 \mathrm{cc}$, in 9 months follow-up prostate volume was $51.78 \pm 8.89 \mathrm{cc}$ and in 12 months follow-up prostate volume was $51.07 \pm 8.94 \mathrm{cc}$. It was also observed that the prostate volume decline was varied from 13.3 to $15.13 \mathrm{ml}$ from baseline to all follow-up. The mean prostate volume was significantly decline in 3 months follow-up and the remaining follow-up prostate volume was also most stable. The mean prostate volume $(\mathrm{cc})$ was statistically significant $(\mathrm{p}<0.05)$ between baseline and each follow-up in these patients, which indicates that after receiving Alfuzosin 10mg with Finasteride $5 \mathrm{mg}$ prostate volume significantly decline in 3 months followup and the remaining follow-up prostate volume was almost stable.

The present study also demonstrated that Alfuzosin with Finasteride combination therapy, were well tolerated. The overall incidence of dropouts due to adverse events was low (3.7\%). Relatively few patients experienced adverse events potentially related to vasodilation, with dizziness the most frequently reported. In a previous study, no clinically relevant changes in blood pressure were observed ${ }^{8}$. The individual adverse effects in the combination-therapy group were similar to those for each drug alone, with the exception of abnormal ejaculation, peripheral edema, and dyspnea. The incidence of orthostatic hypotension was low. This safety profile, especially from a cardiovascular viewpoint, is similar to that observed with Alfuzosin $10 \mathrm{mg}$ OD in a recent European study and reinforces the clinical uroselectivity of Alfuzosin, previously demonstrated in double-blind studies and in general practice ${ }^{12}$.

\section{CONCLUSION}

In this Quasi-experimental trial, combination therapy with Alfuzosin and Finasteride significantly reduced the risk of overall clinical progression of BPH. Combination therapy reduced the long-term risk of acute urinary retention and the need for invasive therapy related to BPH. Combination therapy resulted in a significant improvement in the IPPS symptom score and the maximal urinary flow from baseline. Our results indicate that long-term treatment with combination therapy is both safe and effective therapy for patients with LUTS and $\mathrm{BPH}$, and its use is appropriate in men with an increased risk of progression. However, large, multicentered, double-blind, placebo-controlled, randomized trials are needed to establish the effect of this regimen in the treatment of LUTS due to BPH in Bangladesh. The persistency of the treatment effects will have to be addressed with more frequent and longer follow up period.

\section{DISCLOSURE}

All the authors declared no competing interest. 


\section{REFERENCES}

1. Abrams PH, Griffith DJ. The assessment of prostatic obstruction From urodynamic measurements and from residual urine. Br. J Urol. 1979; 51:129-134.

2. Kaplan SA, Goluboff ET. Effects of demographic factors, urinary peak flow rates, and Boyarsky symptom scores on patient treatment choice in benign prostatic hyperplasia. Urology. 1995; 45: 398-405.

3. McConnell JD. The effect of Finasteride on the risk of acute urinary retention and the need for surgical treatment among men with benign prostatic hyperplasia. N Engl Med. 1998; 338:557-563.

4. Cockett ATK, Aso Y, Denis L et al. Recommendations of the International Consensus Committee, in Cockett ATK, Khoury AS, Aso et al (Eds): Proceedings of the Second International Consultation on Benign Prostatic Hyperplasia (BPH) Paris. Jersey, Scientific Communications International. 1993;553-672.

5. Lefevre-Borg F, O’Connor SE, Schoemaker $\mathrm{H}$ et al. Alfuzosin, a selective alpha 1-adrenoceptor antagonist in thelower urinary tract. $\mathrm{Br} \mathrm{J}$ Pharmacol. 1993;109:1282-1289.

6. Martin DJ, Lluel P, Guillot E, et al. Comparative alpha-1 adrenoceptor subtype selectivity and functional uroselectivity of alpha-1 adrenoceptor antagonists. J Pharmacol Exp Ther. 1997;282:228-235.

7. Martin DJ. Preclinical pharmacology of alpha1-adrenoceptor antagonists. Eur Urol. 1999; 36(Suppl 1):35-41.

8. Debruyne FM, Jardin A, Colloi D. Sustained release Alfuzosin finastende and combination of both in the treatment in benign prostatic hyperplas. Euro Urol. 1998;34:169-175.

9. Kirby RS. Results of the Predict (Prospective European Doxazosin and Combination Therapy) trial. J. Urol. 1999; 161(Suppl 1):266

10. Hofner K: $\alpha_{1}$-Blocker therapy in the nineties: Focus on the disease. Prostate Cancer and Prostatic Disease. 1999;2 (Suppl 4): S9-S15.

11. Djavan B, Marberger M: A meta-analysis on the efficacy and tolerability of $\alpha_{1}$ adrenoceptor antagonists in patients with lower urinary tract symptoms suggestive benign prostatic obstruct symptoms suggestive of benign prostatic obstruction. Eur Urol. 1999;36:1-13.

12. Buzelin JM, Roth S, Geffriaud-Ricouard C et al. For the ALGEBI Study Group: Efficacy and safety of sustained-release Alfuzosin $5 \mathrm{mg}$ in patients with benign prostatic hyperplasia. Eur Urol. 1997;31:190-198. 